\title{
Regional variation in the timing and extent of left ventricular wall motion in normal subjects*
}

\author{
K E HAMMERMEISTER, DEREK G GIBSON, DAVID HUGHES \\ AND PARTICIPANTS IN VETERANS ADMINISTRATION COOPERATIVE STUDY ON \\ VALVULAR HEART DISEASE $\dagger$
}

From the Denver Veterans Administration Medical Center, University of Colorado Health Sciences Center, Denver, Colorado, USA; and Brompton Hospital, London

SUMMARY Right anterior oblique cineangiograms from 19 subjects without evidence of heart disease were analysed to assess regional non-uniformity in the time of onset of systolic inward motion, amplitude of systolic motion, time of peak inward motion, and wall motion during the isovolumic relaxation period. The left ventricular silhouette was digitised frame by frame for a full cardiac cycle. These four wall motion variables were quantitatively measured along 40 chords drawn from equally spaced points on the end diastolic silhouette to the nearest point on the end systolic silhouette. Onset of systolic inward motion was significantly non-uniform, being delayed by up to $120 \mathrm{~ms}$ in the anterior apical chords compared with the areas of earliest inward motion near the base of the heart. More uniformity was noted in time of peak inward motion; the differences between regions were not statistically significant. Amplitude of systolic motion was significantly less at the apical and mid-anterior segments than elsewhere in the heart. Wall motion during the isovolumic relaxation period is outward and greatest in the mid-anterior segments, but inward in the proximal inferior segments and mitral valve region.

These data suggest that contraction of muscle fibres in the anterior apical segments is initially isometric due to the considerable afterload at the onset of contraction, this afterload being the result of earlier contraction elsewhere in the ventricle. This may partly explain the propensity for aneurysms to be located in the anterior apical region. When the timing and extent of wall motion in disease states are analysed, account must be taken of the non-uniformity in the normal heart.

Most angiographic studies of human left ventricular wall motion have examined the extent of wall motion from end diastolic and end systolic frames. This technique does not allow an assessment of the timing of wall motion, the implied assumption being that the onset of systolic and diastolic motion is synchronous in all segments. There is, however, infor-

Requests for reprints to Dr K E Hammermeister, Cardiology Section (111B), Veterans Administration Medical Center, 1055 Clermont, Denver, Colorado 80220, USA.

-Presented to the XII Interamerican Congress of Cardiology, Vancouver, Canada, 19 June 1985.

†A list of participants is available from Dr K E Hammermeister. Accepted for publication 21 April 1986 mation available to indicate that wall motion is neither synchronous nor uniform. ${ }^{1-3}$ Furthermore, if this is correct, similar pathological lesions in different segments of the ventricle might have differing effects on wall motion because the afterload at the onset of wall motion would be different. ${ }^{4}$ This study, in which a computer based frame by frame quantitative analysis of left ventricular angiograms was performed in 19 normal subjects, documents and quantitates the non-uniform nature of both extent and onset of systolic and diastolic wall motion.

\section{Patients and methods}

Patients from the participating hospitals in the Veterans Administration Cooperative Study on Valvu- 
Table 1 Characteristics of the 19 normal subjects

\begin{tabular}{|c|c|c|c|c|c|c|}
\hline Patient & Age & $\begin{array}{l}\text { Indication for } \\
\text { catheter }\end{array}$ & Echo & $E T T$ & $E D V(m l)$ & $E F$ \\
\hline $\begin{array}{l}1 \\
2 \\
3 \\
4 \\
5 \\
6 \\
7 \\
8 \\
9 \\
10 \\
11 \\
12 \\
13 \\
14 \\
15 \\
16 \\
17 \\
18 \\
19 \\
\text { Mean (SD) }\end{array}$ & $\begin{array}{l}36 \\
52 \\
28 \\
47 \\
61 \\
47 \\
59 \\
55 \\
44 \\
40 \\
38 \\
52 \\
60 \\
47 \\
50 \\
53 \\
46 \\
25 \\
47 \\
46 \cdot 7 \\
9.9\end{array}$ & $\begin{array}{l}\text { ACP } \\
\text { Angina } \\
\text { ACP } \\
\text { Angina } \\
\text { Angina } \\
\text { Angina } \\
\text { Angina } \\
\text { Angina } \\
\text { Angina } \\
\text { ACP } \\
\text { Angina } \\
\text { ACP } \\
\text { ACP } \\
\text { ACP } \\
\text { ACP } \\
\text { Angina } \\
\text { Angina } \\
\text { ACP } \\
\text { ACP }\end{array}$ & $\begin{array}{l}\text { NL } \\
\text { TU } \\
\text { NL } \\
\text { NL } \\
\\
\text { TU } \\
\text { TU } \\
\text { NL } \\
\text { NL } \\
\text { NL } \\
\text { NL } \\
\text { NL } \\
\text { NL }\end{array}$ & $\begin{array}{l}\text { NL } \\
\text { NL } \\
\text { NL } \\
\text { NL } \\
+ \text { TL } \\
\text { NL } \\
\text { NL } \\
\text { NL } \\
\text { NL } \\
\text { Eq } \\
\text { NL } \\
\text { NL } \\
\text { NL } \\
+ \text { TL }\end{array}$ & $\begin{array}{r}213 \\
164 \\
82 \\
156 \\
110 \\
206 \\
119 \\
127 \\
149 \\
158 \\
115 \\
169 \\
149 \\
166 \\
152 \\
148 \\
209 \\
145 \\
143 \\
152 \\
34\end{array}$ & $\begin{array}{l}0.54 \\
0.62 \\
0.67 \\
0.80 \\
0.65 \\
0.71 \\
0.51 \\
0.62 \\
0.55 \\
0.65 \\
0.72 \\
0.66 \\
0.69 \\
0.73 \\
0.74 \\
0.65 \\
0.69 \\
0.59 \\
0.69 \\
0.66 \\
0.07\end{array}$ \\
\hline
\end{tabular}

ETT, exercise tolerance test (ST segment response except where indicated); EDV, left ventricular end diastolic volume; EF, ejection fraction; ACP, atypical chest pain; NL, normal (for ETT <1 mm ST depression); TU, technically unsatisfactory; + TL, exercise thallium image interpreted as abnormal; Eq, equivocal ST segment response to exercise.

lar Heart Disease were included if they met the following criteria: right anterior oblique contrast left ventricular angiogram of satisfactory technical quality to outline the ventricular silhouette on each frame for a full cardiac cycle, ejection fraction $\geqslant 50 \%$, no segmental wall motion abnormality on subjective analysis, normal coronary arteriograms, and no other objective evidence of heart disease. The indication for cardiac catheterisation was evaluation of chest pain in all patients. Table 1 lists some characteristics of these 19 patients. Technically satisfactory echocardiograms were available in nine and were normal in all. Exercise tests (Bruce protocol) were performed by 14 patients. One patient had an equivocal ST segment response and two had exercise thallium myocardial images that were reported to be abnormal. These three patients were included because all other cardiac characteristics were normal. Mean heart rate at the time of left ventricular angiography was 65 beats per minute (SD 17, range 42-110).

Left ventricular angiography was performed in the $30^{\circ}$ right anterior oblique projection at frame rates of $30-60$ per second. In six patients simultaneous filming in the $60^{\circ}$ left anterior oblique projection was also obtained. The silhouette of the left ventricular cavity was digitised frame by frame for a full cardiac cycle from a well opacified sinus beat at least one beat removed from a premature beat. ${ }^{5}$ Left ventricular volume was calculated by the area-length method. ${ }^{6}$ Curves of left ventricular volume versus time were smoothed by means of a nine point polynomial best fit; the first derivative was cal-
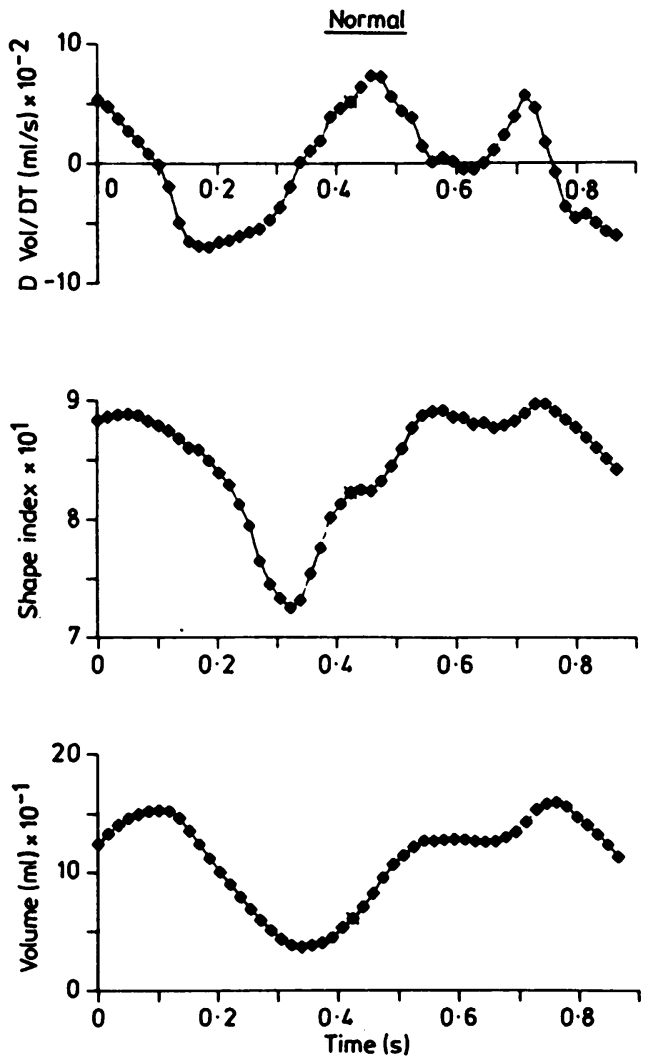

Fig 1 Display of the first derivative of left ventricular volume (DVol/DT), shape index, and volume versus time for a full cardiac cycle in a normal subject. 


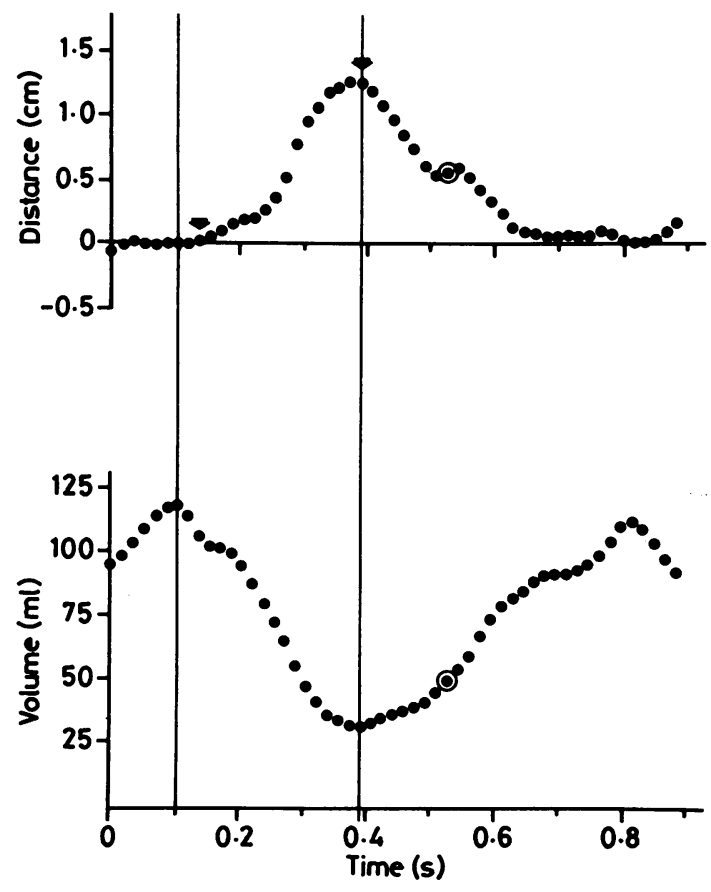

Fig 2 Plot of displacement (upper graph) from end diastolic position versus time of one of 40 equally spaced points on the end diastolic silhouette of the left ventricle in the right anterior oblique projection. Displacement is measured along a chord to the nearest point on the end systolic circumference. Smoothed left ventricular volume curve (lower graph) is shown for comparison. The vertical lines mark the time of end diastole and end systole (maximum and minimum volumes on the smoothed volume curve). The arrows mark the time of onset of inward motion and time of peak motion for this segment on the anterior wall. The circled points indicate the time of mitral valve opening.

culated as previously described to give maximum filling and ejection rates. ${ }^{7}$ Left ventricular shape index was calculated as $4 \pi($ area $) /(\text { perimeter })^{2}$ where a value of 1 describes a circle and lesser values describe increasing eccentricity. ${ }^{8}$ Figure 1 shows plots of left ventricular volume, shape index, and the first derivative of volume versus time ( $\mathrm{D}$ vol/DT) from a normal subject.

To quantify timing and extent of wall motion $\mathbf{4 0}$ equally spaced points (excluding the aortic valve plane) were identified on the end diastolic left ventricular silhouette (frame with largest area). A reference line was constructed from each of these points to the nearest point on the end systolic frame (frame with minimum cavity area). The intersection of the cavity silhouette from each frame throughout a cardiac cycle with one of these reference lines can be displayed as distance from the end diastolic position versus time. ${ }^{9}$ Figure 2 shows an example of one of these displacement curves smoothed by a three point moving average. If each of the plots of displacement versus time for the forty chords about the ventricular circumference are stacked one above another and offset, a visual display of wall motion versus time is obtained, such as that shown in fig 3. The two heavy lines mark end systole (MCA, minimum cavity area) and mitral valve opening (MVO), defined as the frame in which unopacified blood first appears in the left ventricle. The period between these two points is an approximation of the isovolumic relaxation period. Upward motion in the display represents inward wall motion. The same data can be displayed in a more quantitative sense if an isocontour plot is used as shown in fig 4. Each contour line represents $1 \mathrm{~mm}$ of wall motion.

Because of our interest in a critical examination of the timing of onset of systolic and diastolic left ventricular wall motion we felt it important to develop an algorithm which would objectively define the beginning of wall motion; in abnormal states this might be outward (dyskinesis) as well as inward. To avoid confusion between diastolic and systolic motion, both window (time period) and slope criteria were used. The results from the computer determined mathematical algorithms were compared with a visual subjective assignment of onset of

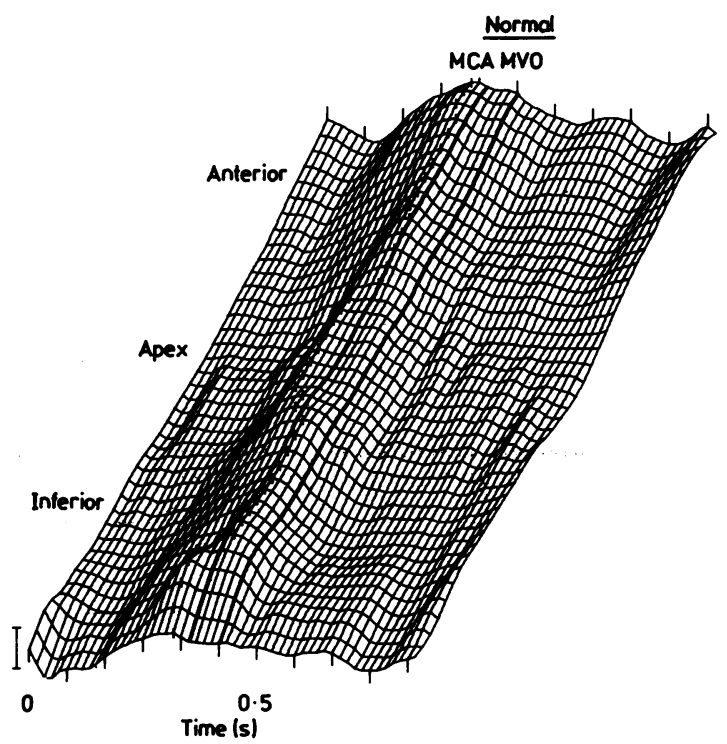

Fig 3 A display of overall ventricular wall motion created by stacking and offsetting each of the $\mathbf{4 0}$ separate displacement curves of wall motion versus time, one of which is shown in the upper part of fig 2. Each light nearly vertical line represents the time of one cine frame. The two heavier nearly vertical lines are end systole (MCA, minimum cavity area) and mitral valve opening (MVO). 


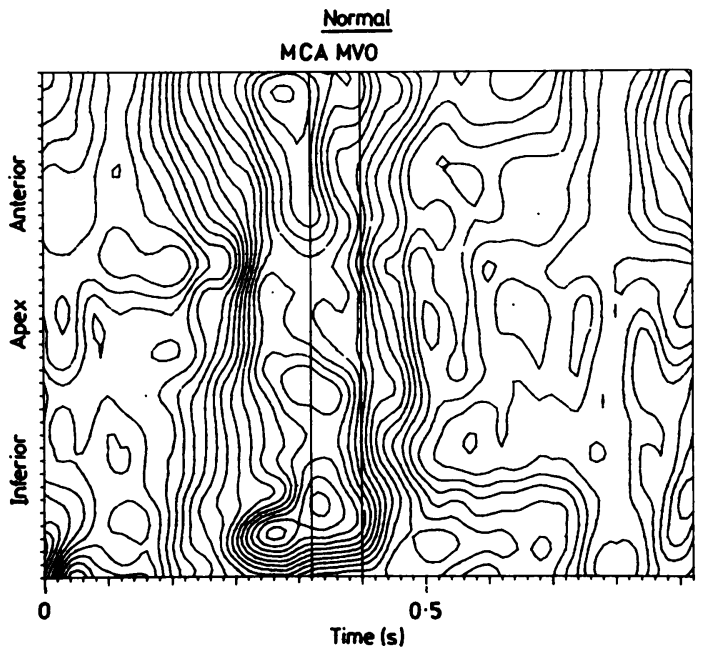

Fig 4 An isocontour plot of wall motion displaying the same data from the same patient shown in fig 3. Each pair of isocontour lines represents wall motion of $1 \mathrm{~mm}$.

a visual subjective assignment of onset of systolic motion from unsmoothed displacement curves.

Several slope and window criteria were compared with the subjective visually determined onset of systolic wall motion in 20 displacement curves from 10 patients. The following criteria gave the best correlations and are those used in this study. For inward motion (positive slope) the onset of motion was defined as the beginning of a $100 \mathrm{~ms}$ period during all of which the slope was $>1.0 \mathrm{~cm} / \mathrm{s}$ and which occurred within the window from $50 \mathrm{~ms}$ before end diastolic volume on the smoothed volume curve to mitral valve opening. If these criteria were not met, important systolic outward motion was sought: this was defined as a slope of at least $-1.0 \mathrm{~cm} / \mathrm{s}$ persisting for at least $100 \mathrm{~ms}$ that occurred within the window from the time of end diastolic volume plus

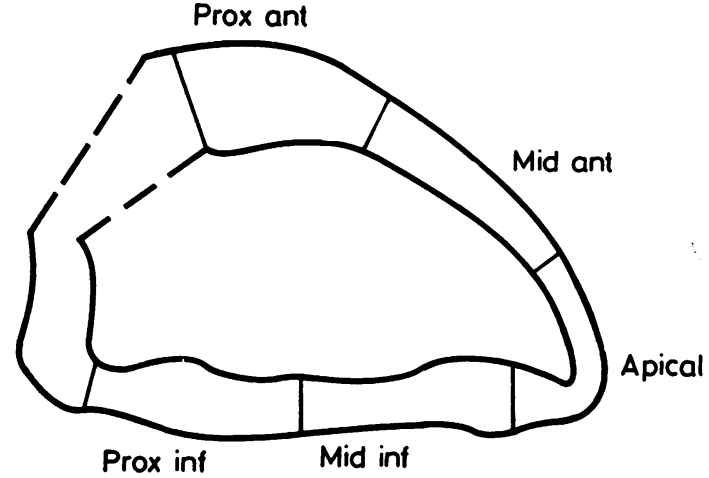

Fig 5 End diastolic and end systolic left ventricular cavity silhouettes superimposed to show the location of the five standard ventricular regions in the right anterior oblique projection.

$30 \mathrm{~ms}$ to the time of end systolic volume. If neither of these criteria was met onset of systolic motion was not determined. For identification of timing of onset of inward and outward wall motion, zero time was defined as the time of maximum volume from the smoothed volume curve.

The time of maximum systolic motion was identified as the time of maximum inward motion if the criteria listed above for onset of inward motion were met, or the time of maximum outward motion if the above criteria for onset of outward motion were met. The amplitude of systolic motion is the net wall motion occurring between the time of onset and time of peak systolic motion. Similarly, wall motion during the isovolumic relaxation period is the net wall motion between end systole (the frame of minimum cavity area) and mitral valve opening. Outward motion, the usual direction during the isovolumic relaxation period, carries a positive sign.

The wall motion data were presented in two ways.

Table 2 Quantitative wall motion variables (mean (SD)) for five standard regions of the right anterior oblique left ventricular angiogram

\begin{tabular}{|c|c|c|c|c|}
\hline \multirow[b]{2}{*}{ Region } & \multicolumn{2}{|l|}{ Interval from $T E D V$ (ms) } & \multicolumn{2}{|c|}{ Amplitude of motion (cm) } \\
\hline & Onset of systolic motion & Peak systolic motion & Systolic motion & IVR motion \\
\hline $\begin{array}{l}\text { Proximal anterior (chords 33-39) } \\
\text { Mid-anterior (chords 26-32) } \\
\text { Apical (chords 19-25) } \\
\text { Mid-inferior (chords 13-18) } \\
\text { Proximal inferior (chords 6-12) }\end{array}$ & $\begin{array}{r}27(28) \\
57(44) \\
102(61) \\
37(47) \\
28(35)\end{array}$ & $\begin{array}{l}376(64) \\
375(64) \\
405(63) \\
405(77) \\
426(64)\end{array}$ & $\begin{array}{l}1.24(0.30) \\
0.85(0.25) \\
1.11(0.39) \\
1.15(0.30) \\
1.14(0.36)\end{array}$ & $\begin{array}{l}0.29(0.17) \\
0.25(0.16) \\
0 \cdot 22(0.25) \\
0 \cdot 24(0.17) \\
0.02(0.15)\end{array}$ \\
\hline $\begin{array}{l}\text { One way analysis of variance: } \\
F \\
\text { df } \\
p\end{array}$ & $\begin{array}{l}9.17 \\
4,90 \\
<0.001\end{array}$ & $\begin{array}{l}1 \cdot 40 \\
4,90 \\
0 \cdot 240\end{array}$ & $\begin{array}{l}3.96 \\
4,90 \\
0.005\end{array}$ & $\begin{array}{l}6.09 \\
4,90 \\
<0.001\end{array}$ \\
\hline
\end{tabular}

TEDV, time of first left ventricular end diastolic volume from smoothed left ventricular volume curve; IVR, isovolumic relaxation period (see text for definitions). 


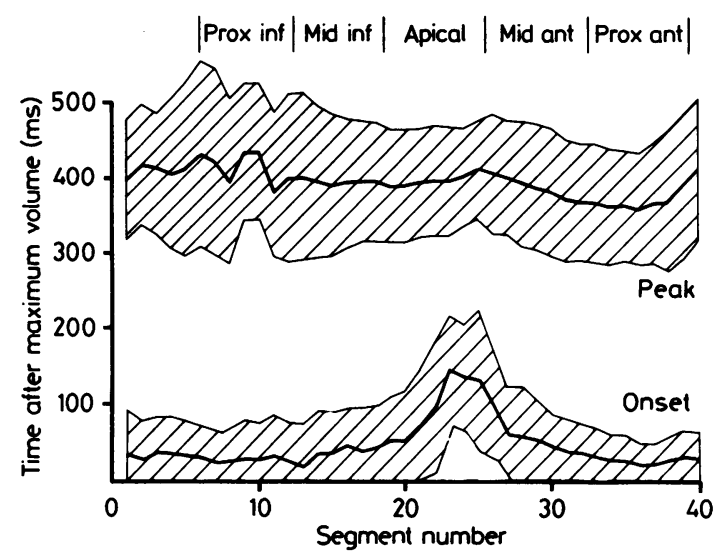

Fig 6 Mean time of onset of systolic motion and time of peak systolic motion are plotted against segment number for the 19 normal subjects (heavy lines). Cross hatched area shows one standard deviation about the mean. Zero time is the time of end diastolic volume on the smoothed volume curve.

The four wall motion variables were plotted against the serial number of each of the forty equally spaced chords about the ventricular circumference. Also the data for the six or seven chords in each of the five standard ventricular segments in the right anterior oblique projection ${ }^{10}$ were averaged (table 2). Figure 5 shows the location of these five regions.

To assess the statistical significance of nonuniformity of left ventricular wall motion, one way analysis of variance was used to compare the five ventricular segments with one another.

\section{Results}

Figure 6 shows the data for time of onset and time of peak systolic motion (mean (1SD)) for each of the 40 chords about the ventricular circumference for the 19 subjects. The time of onset of systolic motion varies by $126 \mathrm{~ms}$ from 18 (56) ms after end diastolic volume for chord number 13 in the mid-inferior segment to 144 (72) ms for chord number 23 in the apical segment. Table 2 shows the data for the five ventricular segments obtained by averaging the data from the six or seven chords within each segment. Although the averaging of chords reduces the differences, the non-uniformity of time and amplitude is still apparent. The time of onset of systolic motion varies from $27(28) \mathrm{ms}$ for the proximal anterior segment to 102 (61) $\mathrm{ms}$ for the apical segment $(\mathrm{p}<0.001)$.

The time of peak systolic motion is more uniform than time of onset (fig 6). The earliest time of peak systolic motion (358 (75) ms) occurs in chord num-

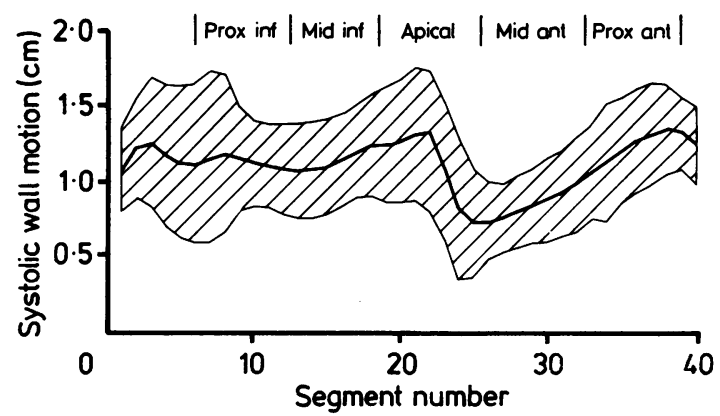

Fig 7 Mean amplitude of systolic wall motion (heavy line) plus or minus one standard deviation (cross hatched area) plotted against segment number for the 19 normal subjects.

ber 36 in the proximal anterior segment, a region showing relatively early onset of motion. The latest time of peak motion (435 (92) ms), however, occurs in chord number 10 in the proximal inferior segment, a segment in which onset of motion is also relatively early. When the chord data are averaged to give values for the five segments, the time of peak systolic motion varies only from $375(64) \mathrm{ms}$ for the mid-anterior segment to $426(64) \mathrm{ms}$ for the proximal inferior segment $(p=0.240$; table 2$)$.

The amplitude of systolic motion also appears to be non-uniform by this technique, which makes no attempt to correct for shift in the major axis of the ventricle with systole (fig 7). Amplitude varies from $1.35(0.30) \mathrm{cm}$ in chord number 38 in the proximal anterior segment to $0.73(0.36) \mathrm{cm}$ in chord number 25 in the apical segment. The values for the five segments vary from $1.24(0.30) \mathrm{cm}$ for the proximal

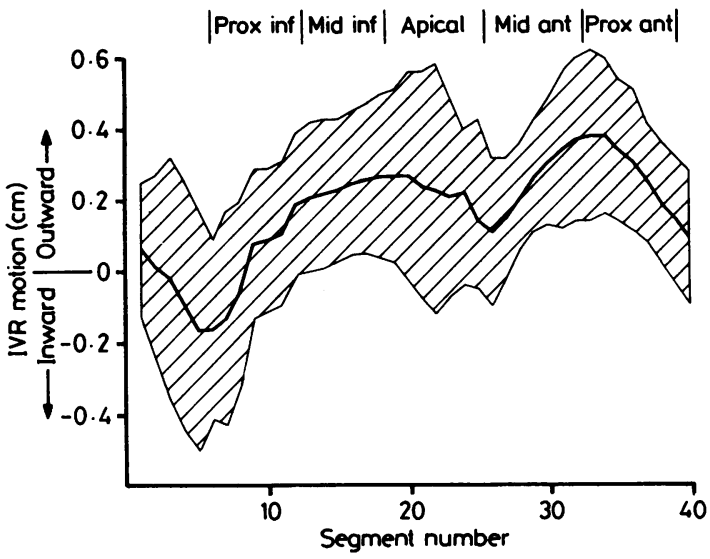

Fig 8 Mean wall motion (heavy line) plus or minus one standard deviation (cross hatched area) during the isovolumic relaxation period (defined by minimum cavity area and mitral valve opening) plotted against segment number for the 19 normal subjects. Outward motion is plotted as a positive value. 
anterior segment to $0.85(0.25) \mathrm{cm}$ for the midanterior segment (table 2). The differences in amplitude of motion between segments are highly significant ( $p=0.005)$.

Wall motion during the isovolumic relaxation period is also non-uniform (fig 8), varying from 0.38 $(0.22) \mathrm{cm}$ (outward) for chords number 33 and 34 in the proximal anterior segment to $-0.16(0.34) \mathrm{cm}$ (inward) for chord number 6 in the proximal inferior segment. Displacement for chords $1-5$ in the mitral valve region is also generally inward. When examined by segments, motion during the isovolumic relaxation period is relatively uniform for all segments $(0.22-0.29 \mathrm{~cm})$ except the proximal inferior segment $(0.02(0.15) \mathrm{cm})$. This non-uniformity of motion between segments is statistically significant $(\mathrm{p}<0.001$; table 2$)$.

\section{Discussion}

Our objective analyses of left ventricular wall motion in normal subjects indicate that both amplitude and timing of wall motion are non-uniform about the circumference in the right anterior oblique projection. The onset of systolic motion in the apical chords is delayed by up to $126 \mathrm{~ms}$ compared with the chords with the earliest onset. In the apical and anterior chords, the amplitude of systolic motion is reduced to as little as $54 \%$ of that in the chords with the greatest amplitude. The distribution of chords with reduced amplitude, however, does not correspond to that with delayed onset of systolic motion. Wall motion during the isovolumic relaxation period is also non-uniform with the mitral valve region and proximal inferior segment demonstrating inward motion, while the other segments show outward motion.

\section{ONSET OF SYSTOLIC MOTION}

As shown in fig 6 and table 2, the onset of systolic motion is relatively synchronous for the proximal inferior, proximal anterior, and the mid-inferior segments. In the apical and mid-anterior segments, however, onset of systolic motion is significantly delayed. Artefact of the method due to shift of the axis of the ventricle during contraction, delay in electrical activation, and initial isometric contraction are possible explanations for this delay.

With systole the major axis of the left ventricle appears to shift anteriorly and laterally (vide infra). Various schemes of realignment have been proposed to correct for this shift, none of which are entirely satisfactory. Rather than make any assumptions about major axis shift, the motion of the left ventricular cavity silhouette was analysed in the present study without realignment. If an anterolateral major axis shift occurs this could result in apparent hypokinesis of the mid-anterior segment and hyperkinesis of the mid-inferior segment. While amplitude of systolic motion of the mid-anterior segment $(0.85 \mathrm{~cm})$ is less than that of the other segments $(1.11-1.24 \mathrm{~cm})$, the amplitude of motion of the midinferior segment $(1.15 \mathrm{~cm})$ is not increased compared with other segments except for the midanterior segment.

An anterior-lateral long axis shift producing apparent hypokinesis might also produce an apparent delay in onset of inward motion in the midanterior segment. This mechanism, however, cannot account for the delay in the apical segment because wall motion in this segment is generally parallel to the shifting long axis. In fact the delay in the apical segment is almost three times the delay observed in the mid-anterior segment $(75 \mathrm{~ms}$ vs $30 \mathrm{~ms})$. Some of the observed hypokinesis in the mid-anterior segment could be the result of axis shift, but the axis shift cannot explain the delay in onset of inward motion in the apical segment. We conclude that the delay in onset of systolic motion at the apex is not an artefact of the method.

In 1978 Gibson et al noted the asynchrony in onset of inward motion in normal subjects. ${ }^{3}$ Subsequently Clayton et al and Klausner et al have also reported delayed onset of contraction at the apex. ${ }^{211}$ The maximum asynchrony in their study was $25 \mathrm{~ms}$, however, much less than the $126 \mathrm{~ms}$ in the present study. There are significant differences in methods that may account for this discrepancy: Clayton and Klausner and colleagues constructed a major axis for each frame (that is the equivalent of realigning on the long axis), and time of onset was taken as the longest chord or radius rather than as a specified slope. Use of the longest chord rather than a slope to indicate onset is much more sensitive to noise, such as incorrect identification of the silhouette position in a single frame. The magnitude of the asynchrony in the present study is similar to that previously reported from this laboratory based on analysis of contour plots only ${ }^{3}$ (for example fig 4).

The mechanism of the delay in apical systolic motion is of considerable interest. Although delay in electrical activation may be contributory, this should account for only a fraction of the $126 \mathrm{~ms}$ delay observed. Durrer and colleagues report that the apex was activated 45 to $50 \mathrm{~ms}$ after the earliest site of ventricular activation. ${ }^{12}$ Of course, asynchronous electrical activation of the ventricle has long been known. ${ }^{1314}$ Dissociation between electrical activation and mechanical contraction has been reported in experimental intact heart preparations. In an experimental study electrical activation of the anterior papillary muscle occurred $6 \mathrm{~ms}$ before 
the anterior epicardial site, but mechanical contraction of the anterior papillary muscle was delayed $27 \mathrm{~ms}$ in relation to anterior epicardium, a discrepancy of $33 \mathrm{~ms}^{1516}$ If delay in electrical activation was the prime reason for the asynchronous onset of inward wall motion, then some regions of the ventricle should be moving outward as others move inward because unactivated regions cannot develop tension as pressure is beginning to rise. Such "paradoxical" motion has been observed in patients with coronary artery disease, ${ }^{3}$ but was not seen in our normal subjects.

We believe isometric contraction occurring in early systole at the apex is the most likely explanation to account for the discrepancy between electrical asynchrony of about $50 \mathrm{~ms}$ and mechanical asynchrony of up to $126 \mathrm{~ms}$. The delay in electrical activation $(40-50 \mathrm{~ms})$ means that the apical myocardium is initiating contraction against a considerable afterload because of earlier contraction elsewhere. Furthermore, the relatively thin myocardium at the apex may require a longer time of isometric contraction to overcome the afterload and shorten. Myocardial architecture and fibre orientation as well as wall thickness probably also have a role. Motion of the anterior and inferior regions is due to circumferentially directed fibres, while that of the apex is due to longitudinally directed fibres. The physiological significance of these two types of fibres was lucidly discussed by Sir Arthur Keith as early as 1918. ${ }^{17}$

\section{AMPLITUDE OF WALL MOTION}

The amplitude of systolic wall motion is relatively uniform in the proximal inferior and mid-inferior chords $(1 \cdot 1-1.3 \mathrm{~cm})$, falls markedly to about $0.7 \mathrm{~cm}$ in the anterior apical and adjacent mid-anterior chords, and returns to $1.1-1.3 \mathrm{~cm}$ in the proximal anterior chords (fig 7). If this non-uniformity were to be explained solely by a shift in the major axis anteriorly and laterally, one would expect the amplitude in the mid-inferior region to be increased by an amount equivalent to the decrease in the midanterior region. This is not the case; amplitude in the mid-inferior segment is essentially the same as that of other segments, except for the mid-anterior segment which exhibits a 3-4 mm decrease in amplitude of motion. The failure to see increased amplitude in the mid-inferior segment suggests that the angular shift of the long axis of the left ventricle in the $30^{\circ}$ right anterior oblique projection is substantially less than the $4^{\circ}$ previously reported, ${ }^{18} 19$ since an angular shift of this magnitude would produce an increase of approximately $4 \mathrm{~mm}$ in amplitude in the mid-inferior segment. In fact the absence of inferior hyperkinesis suggests that the apparent shift of the long axis may be an illusion caused by the normal hypokinesis of the apical and mid-anterior region. Endocardial motion is closely related to changes in wall thickness, ${ }^{20}$ again indicating that displacement of the entire ventricle cannot be used to explain endocardial wall motion.

Finally, we considered whether translation of the ventricle along the major axis toward the apex during systole could contribute to the reduced wall motion at the apex. The aortic valve plane descends in systole $(1.30(0.32) \mathrm{cm}$ in these 19 normal subjects) as was described by Keith in $1907^{21}$; but this is the same as the amplitude of motion seen in apical chords 19-22. Thus at the very apex and the aortic valve the ventricular silhouette seems to move equally towards its centre of mass. Nevertheless, the descent of the aortic valve over the bolus of blood in the left ventricle undoubtedly contributes energy to aortic blood flow by virtue of passive elastic recoil during diastole. The descent of the aortic valve plane, however, does not seem to contribute to the reduced wall motion amplitude, which is greatest anterior to the major axis.

Several other experimental and clinical studies have also shown reduced amplitude of wall motion in the apical region despite various realignment schemes. ${ }^{18192223}$ We conclude that the reduction in wall motion amplitude in the anterior apical region cannot be satisfactorily explained by an axis shift. For the reasons given in the discussion of time of onset of systolic motion it seems likely that contraction here must be initially isometric.

\section{TIMING OF PEAK SYSTOLIC MOTION}

The time of peak systolic motion is somewhat earlier in the mid and proximal anterior regions than elsewhere. As shown in fig 6, there is no relation between time of onset of systolic motion and time of peak systolic motion. This provides further evidence for a dissociation between electrical and mechanical events, since repolarisation generally occurs in a reverse sequence from depolorisation, with repolarisation occurring earliest at the apex.

\section{WALL MOTION DURING ISOVOLUMIC}

RELAXATION

Our data indicate apparent outward wall motion during isovolumic relaxation for most of the circumference of the left ventricle in the right anterior oblique projection (fig 8, table 2). Since ventricular volume cannot change during the true isovolumic relaxation period, several methodological explanations must be considered: (a) overestimation of the true isovolumic relaxation period; (b) opposite compensatory shape change in the orthogonal plane (that is, inward motion in the left anterior oblique 
projection); and (c) inward movement of the mitral valve before actual mitral valve opening.

True isovolumic relaxation time measured from aortic valve closure to mitral valve opening by phonocardiography and echocardiography in normal subjects is $58-65 \mathrm{~ms}^{2425}$ When the angiographic definition (time of minimum volume of the smoothed volume curve to first appearance of unopacified blood in the left ventricle) was used, however, isovolumic relaxation was $116(41.5) \mathrm{ms}$.

In the six patients in whom simultaneous left anterior oblique filming was available, we examined motion during isovolumic relaxation in five segments about the circumference of the ventricle. In no segment was mean motion inward. Average motion over all five segments was $0.17 \mathrm{~cm}$ outward, indicating that there was not net inward motion in the orthogonal plane. Inward motion during isovolumic relaxation does occur in the mitral valve region (fig 8, chords 1-5), but is of insufficient magnitude to account for outward motion during isovolumic relaxation over most of the remaining circumference of the ventricle in the absence of volume change. Thus our angiographic definition of isovolumic relaxation probably included early diastolic filling, a conclusion supported by the observation of Marier and Gibson that peak inward wall motion does not coincide with aortic valve closure. ${ }^{26}$

Nevertheless, the distribution of outward motion during isovolumic relaxation is of interest. It is greatest in chords 29-37 on the anterior wall (fig 8), the same segments in which abnormal degrees of outward movement are most commonly seen in patients with ischaemic heart disease. ${ }^{97-31}$ This appears to be the region in which the early release of passive elastic restoring forces is most likely to occur.

PHYSIOLOGICAL AND CLINICAL IMPLICATIONS Delay in onset of motion at the apex implies that cavity volume falls because the minor axis shortens; this results in the cavity becoming less spherical, as previously reported. ${ }^{8}$ A portion of this minor axis shortening occurs before aortic valve opening. ${ }^{32}$ These observations can be related to the physiology of energy transfer. The major portion of energy transfer from the left ventricle to the ejected bolus of blood occurs in the first third of systole, as this is when blood is being accelerated to overcome inertia. ${ }^{3334}$ Thus it is the circumferential fibres in the basal and mid-ventricular regions that are largely responsible for energy transfer. The apex starts to move inward at a time when blood flow is largely inertial and requires little additional energy to maintain flow.

Early diastolic motion is probably in part the result of the release of stored potential energy accumulated during systole by deformation of elastic components in the ventricular wall. The rate and magnitude of such energy release would be highly dependent of myocardial fibre architecture and overall wall geometry, which is both complex and non-uniform. Thus a close relation between onset of outward motion and inward motion would not be expected and was not found.

The normal delay in onset of inward motion and the reduced amplitude of motion in the anterior apical region may be a partial explanation for the propensity for aneurysm formation in this region. The reduction in radius of curvature with reduction in cavity size is a mechanism for reducing myocardial fibre stress during systole. The normal delay in onset of inward motion in the anterior apical region implies that myocardial fibre stress may be increased in early systole here (that is to the extent that isometric contraction occurs). The reduced amplitude of inward motion results in maintenance of high systolic stresses for a prolonged period in normal subjects, as the increase in wall thickness and reduction in radius of curvature that reduce systolic stress elsewhere are delayed at the apex. It appears that myocardial fibre systolic stress is much more heterogeneous throughout the ventricle than most mathematical models imply; this has important implications for the response to pathological processes. With only a modest degree of myocardial damage the initial isometric contraction may be prolonged throughout systole resulting, in akinesis. With greater myocardial damage the anterior apical fibres are unable to maintain even a constant length during systole and systolic bulging or dyskinesis occurs.

In coronary artery disease the generally larger infarct size with anterior infarctions is another explanation for the location of aneurysm in the anterior apical region. On the other hand, the normally prolonged high systolic stresses in this region may contribute to increased myocardial necrosis because myocardial fibre stress is a major determinant of myocardial oxygen demand.

In the earlier stages of Chagas's disease, aneurysms are seen primarily in the anterior apical region, ${ }^{4}$ although there is no reason to believe that the initiating infectious process is similarly localised. The inferior hypokinesis that we observed in patients with early Chagas's disease ${ }^{4}$ and the observation that late stages of the disease give a diffuse dilated cardiomyopathic pattern are further evidence of the generalised nature of the infectious process. Here too, the normal non-uniformity of myocardial architecture, timing, extent of motion, and myocardial stress offer an explanation for localisation of aneurysm formation to the apex. 
Finally, the normal non-uniformity of wall motion makes subjective assessment of lesser degrees of segmental dysfunction difficult, if not impossible. Systolic wall motion in the anterior apical region of $0.5 \mathrm{~cm}$ or one half of that elsewhere in the ventricle falls within one standard deviation of the normal mean for this region (fig 7). Thus subjective interpretation might result in a diagnosis of anteroapical hypokinesis, when wall motion is no different from normal. More importantly, abnormalities in timing of wall motion both at the onset of systole and during relaxation often occur in clinical heart disease, but their possible effect on prognosis have been little explored. Abnormal coordination of wall motion depends upon the recognition of the asynchronous nature of wall motion in normal subjects.

In conclusion, careful quantitative analysis of left ventricular wall motion in normal subjects showed that both the timing and extent of wall motion are non-uniform. The normal delay in electrical activation of the apex means that afterload is already considerable when contraction begins. The obligatory electrical delay superimposed on regional differences in myocardial fibre structure and orientation ${ }^{35}$ results in initial isometric contraction, which further delays the onset of inward wall motion in the anterior apical region by as much as $126 \mathrm{~ms}$ over the area of earliest wall motion and reduces the amplitude of inward motion. The non-uniformity of structure and function of the left ventricle implies that the many models used to calculate wall stress, compliance or stiffriess, and many other variables, which are based on the assumption of uniformity, are not necessarily tenable. With the pronounced differences in timing and amplitude of motion between regions of the normal ventricle, it could be expected that similar pathological processes might produce different wall motion patterns depending on the regions involved, as we have observed in patients with Chagas's disease. ${ }^{4}$ Finally, the assessment of regional left ventricular function requires a recognition of the normal regional non-uniformity of timing and amplitude of motion. The present study provides a basis for comparing the timing and extent of wall motion in various diseases.

This research was supported by Veterans Administration institutional funds and by the British Heart Foundation.

\section{References}

1 Greenbaum RA, Gibson DG. Regional non-uniformity of left ventricular wall movement in man. Br Heart $\mathcal{F}$
1981;45:29-34.

2 Clayton PD, Bulawa WF, Klausner SC, Urie PM, Marshall HW, Warner HR. The characteristic sequence for the onset of contraction in the normal left ventricle. Circulation 1979;59:671-9.

3 Gibson DG, Doran JH, Traill TA, Brown DJ. Abnormal left ventricular wall movement during early systole in patients with angina pectoris. Br Heart $\mathcal{f}$ 1978;40:758-66.

4 Hammermeister KE, Caeiro T, Crespo A, Palmero H, Gibson DG. Left ventricular wall motion in patients with Chagas's disease. Br Heart $\mathcal{F}$ 1984;51:70-6.

5 Gibson DG, Brown DJ. Measurement of peak rates of left ventricular wall movement in man. Comparison of echocardiography with angiography. $\mathrm{Br}$ Heart $\mathcal{f}$ 1975;37:677-83.

6 Dodge HT, Sandler H, Ballew DW, Lord JD. The use of biplane angiocardiography for the measurement of left ventricular volume in man. Am Heart $\mathcal{F} 1970$; 60:762-76.

7 Hammermeister KE, Brooks RC, Warbasse JR. The rate of change of left ventricular volume in man. I. Validation and peak systolic ejection rate in health and disease. Circulation 1974;49:729-38.

8 Gibson DG, Brown DJ. Continuous assessment of left ventricular shape in man. $B r$ Heart $\mathcal{f}$ 1975;37: 904-10.

9 Gibson DG, Prewitt TA, Brown DJ. Analysis of left ventricular wall movement during isovolumic relaxation and its relation to coronary artery disease. $\mathrm{Br}$ Heart $\mathcal{F}$ 1976;38:1010-9.

10 Austen WG, Edwards JE, Frye RL, et al. A reporting system on patients evaluated for coronary artery disease. Circulation 1975;51(pt 2):1-40.

11 Klausner SC, Blair TJ, Bulawa WF, Jeppsen GM, Jensen RL, Clayton PD. Quantitative analysis of segmental wall motion throughout systole and diastole in the normal human left ventricle. Circulation 1982;65:580-90.

12 Durrer D, van Dam RT, Freud GE, Janse MJ, Meijler FL, Arzbaecher RC. Total excitation of the isolated human heart. Circulation 1970;41:899-912.

13 Lewis T, Rothschild MA. The excitatory process in the dog's heart. Part II. The ventricles. Philos Trans $R$ Soc Lond [Biol] 1915;206:181-226.

14 Wiggers CJ. The interpretations of the intraventricular pressure curve on the basis of rapidly summated fractionate contractions. Am F Physiol 1927;80:1-11.

15 Cronin R, Armour JA, Randall WC. Function of the in situ papillary muscle in the canine left ventricle. Circ Res 1969;25:67-75.

16 Armour JA, Randall WC. Electrical and mechanical activity of papillary muscle. Am $\mathcal{f}$ Physiol 1970;218:1710-7.

17 Keith A. The functional anatomy of the heart. Br Med f 1918;i:361-3.

18 Sniderman AD, Marpole D, Fallen EL. Regional contraction patterns in the normal and ischemic left ventricle in man. Am $\mathcal{F}$ Cardiol 1973;31:484-9.

19 Brower RW, Meester GT. Computer based methods for quantifying regional left ventricular wall motion from cine ventriculograms. Computers in Cardiology 
1976:55-62.

20 Gibson DG, Traill TA, Brown DJ. Changes in left ventricular wall thickness in patients with ischaemic heart disease. Br Heart $\mathcal{f}$ 1977;39:1312-8.

21 Keith A. An account of the structures concerned in the production of the jugular pulse. $\mathcal{F}$ Anat Physiol 1907;42:1-25.

22 Harris LD, Clayton PD, Marshall HW, Warner HR. A technique for the detection of asynergic motion in the left ventricle. Comput Biomed Res 1974;7:380-94.

23 Bhargava V, Warren S, Vieweg WVR, Shabetai R. Quantitation of left ventricular wall motion in normal subjects: comparisons of various methods. Cathet Cardiovasc Diagn 1980;6:7-16.

24 Lewis BS, Lewis N, Sapoznikov D, Gotsman MS. Isovolumic relaxation period in man. Am Heart $\mathcal{f}$ 1980;100:490-9.

25 Chen W, Gibson D. Relation of isovolumic relaxation to left ventricular wall movement in man. Br Heart $\mathcal{f}$ 1979;42:51-6.

26 Marier DL, Gibson DG. Limitations of two frame method for displaying regional left ventricular wall motion in man. Br Heart $\mathcal{F} 1980 ; 44: 555-9$.

27 Altieri PI, Woit SM, Leighton RF. Left ventricular wall motion during the isovolumic relaxation period. Circulation 1973;48:499-505.

28 Ruttley MS, Adams DF, Cohn PF, Abrams HL.
Shape and volume during "isovolumic relaxation" in normal and asynergic ventricles. Circulation 1974;50:306-16.

29 Wilson CS, Kraeger S. Forker AD, Weaver WF. Correlations between segmental early relaxation of the left ventricular wall and coronary occlusive disease. Am Heart $\mathcal{F}$ 1975;89:474-9.

30 Alan SE, Tansey WA, Cameron A, Kemp HA Jr. Asynchronous ventricular relaxation: an angiographic temporal analysis of asynchronous left ventricular relaxation in man. Am $\mathcal{F}$ Cardiol 1979; 43:41-6.

31 Gibson DG, Greenbaum R, Marier DL, Brown DJ. Clinical significance of early diastolic changes in left ventricular wall thickness. Eur Heart $\mathcal{f}$ 1980;1:A-157-63.

32 Karliner JS, Bouchard RJ, Gault JM. Dimensional changes of the human left ventricle prior to aortic valve opening. Circulation 1971;44:312-22.

33 Spencer MP, Greiss FC. Dynamics of ventricular ejection. Circ Res 1962;10:274-9.

34 Rushmer RF. Initial ventricular impulse. A potential key to cardiac evaluation. Circulation 1964;29: 268-83.

35 Greenbaum RA, Ho SY, Gibson DG, Becker AE, Anderson RH. Left ventricular fibre architecture in man. Br Heart $\mathcal{F}$ 1981;45:248-63. 